\title{
A Case of Congenital Goiter and Pulmonary Dysplasia
}

\author{
Venkata Suresh Golla ${ }^{1}$, V Lakshmi², Hemchand K Prasad ${ }^{3}$ \\ ${ }^{1}$ DNB Neonatology Resident, Dr. Mehta’s Multispeciality Hospital India Pvt Ltd, Chennai, India \\ ${ }^{2}$ HOD, Department of Neonatology, Dr. Mehta's Multispeciality Hospital India Pvt Ltd, Chennai, India \\ ${ }^{3}$ Pediatric Endocrinologist, Dr. Mehta's Multispeciality Hospital India Pvt Ltd, Chennai, India
}

\begin{abstract}
Pulmonary hypoplasia is a rare condition and usually fatal. We present a 34 week, late preterm female neonate with congenital hypothyroid goiter who was presented with severe respiratory distress at birth and required mechanical ventilation support. Baby had severe hypoxemia and features of respiratory distress syndrome and low volume lungs on chest $x$ ray. Baby died of hypoxemic respiratory failure and severe pulmonary arterial hypertension at 77 hours of life. Lung hypoplasia was diagnosed on autopsy.
\end{abstract}

Keywords: Congenital goiter, persistent pulmonary hypertension, pulmonary hypoplasia

\section{Introduction}

Pulmonary hypoplasia is the end result of deficient lung development leading to a decreased number of small airways, alveoli, and pulmonary blood vessels [1]. It is classified as primary and secondary pulmonary hypoplasia. Primary pulmonary hypoplasia is abnormal development of lung due to abnormalities of the transcription factors and growth factors that regulate early lung morphogenesis. Secondary pulmonary hypoplasia is compromised lung development secondary to reduction of the chest cavity by a mass, pleural effusion, external compression or oligohydramnios due to fetal renal anomalies, early rupture of membranes, or the absence of fetal breathing movements $[2,3]$. Congenital goiter is an enlarged thyroid gland in a neonate which may be associated with hyperthyroidism, hypothyroidism, or even euthyroidism [4]. Thyroid hormone plays a crucial role in lung development. A large fetal goiter can impair fetal swallowing and breathing movements during antenatal period and postnatally the neonate may present with respiratory distress at birth due to compromised airway.

We present a case of congenital hypothyroid goiter in a neonate, who presented with respiratory distress at birth. The baby was died of hypoxemic respiratory failure and pulmonary hypoplasia was diagnosed at autopsy.

\section{Case Report}

A 35 week female neonate was born to a 26 years old $G_{2} P_{1}$ mother by spontaneous preterm vaginal delivery. She was born out of $3^{\text {rd }}$ degree consanguineous parentage. The pregnancy was uneventful up to 26 weeks of gestation at which fetal thyromegaly (size $0.6 \mathrm{~cm} \times 1.3 \mathrm{~cm}$ ) was noticed during the routine ultrasonographic examination. Maternal past medical history was not significant and she had no thyroid disease. Mother had a history of neonatal death in the previous pregnancy in which she gave birth to a female baby with a birth weight of $2.8 \mathrm{~kg}$ by normal vaginal delivery at 40 weeks of gestation. Baby had visible neck swelling at birth and died at 1 hour of life due to respiratory distress.
In the present pregnancy, mother was evaluated in view of fetal thyromegaly. Maternal thyroid profile was normal. Maternal TPO (thyroid peroxidase), TRab (TSH receptor antibodies) and Anti thyroglobulin antibodies levels were normal. Follow up scan after 2 weeks showed increase in the size of fetal thyroid $(2.3 \times 4.54 \mathrm{~cm})$ and polyhydramnios suggesting difficulty in fetal swallowing of amniotic fluid. Fetal Doppler studies were normal. Fetal thyroid profile was done by percutaneous umbilical cord blood sampling (PUBS) which showed low free T4 $(0.44 \mathrm{ng} / \mathrm{dl})$ and grossly elevated TSH $(>100 \mathrm{mIU} / \mathrm{ml})$ suggestive of fetal hypothyroidism. Fetal karyotype done was normal. Two doses of intra amnioitic Levothyroxin was administered at a dose of $200 \mu \mathrm{g}$ at an interval of 2 weeks (at $31+2$ and $33+2$ weeks) at Mediscan systems, Chennai. Subsequent ultrasonograms showed reduction in the size of goiter. Fetal echo showed apical muscular VSD (ventricular septal defect) and mild tricuspid regurgitation. Mother has received antenatal corticosteroids for fetal lung maturity.

Mother went into spontaneous labor at 35 weeks of gestation and delivered a female baby with a birth weight of $2.01 \mathrm{~kg}$ (between $10^{\text {th }}$ to $50^{\text {th }}$ centile), head circumference of $33 \mathrm{~cm}$ (between $50^{\text {th }}$ to $90^{\text {th }}$ centile), length of $46 \mathrm{~cm}$ (between $50^{\text {th }}$ to $90^{\text {th }}$ centile). APGAR score at 1 minute and 5 minutes were $7 / 10$ and $8 / 10$ respectively. On examination baby had $5 \times 4 \mathrm{~cm}$ neck swelling, which is firm and nodular in consistency. Baby had dysmorphic facies with flat occiput, broad and high forehead, small and anteverted nose and single horizontal palmar crease in the right hand.

Baby developed respiratory distress soon after birth for which baby was intubated and started on positive pressure ventilation. Mechanical ventilation was continued in SIPPV mode (synchronized intermittent positive pressure ventilation) with a PEEP-5 $\mathrm{cm} \mathrm{H}_{2} \mathrm{O}$, PIP- $16 \mathrm{~cm} \mathrm{H}_{2} \mathrm{O}$, Rate$40 \mathrm{bpm}, \mathrm{FiO}_{2}-50 \%$. A dose of surfactant was administered intratracheally in view of high Fio2 requirement and chest $\mathrm{x}$ ray suggestive of respiratory distress syndrome (Figure 2). Blood gas showed PH-7.184, PCO2-58.4mmHg, PO262.2 $\mathrm{mmHg}$, Bicarbonate $18.3 \mathrm{mEq} / \mathrm{L}$, Base Excess- -7.4. Thyroid profile showed hypothyroidism (FT4-0.5ng/dl, TSH- $126.2 \mathrm{microIU} / \mathrm{ml}$ ) for which baby was started on oral 
thyroxin 50mcg/day after pediatric endocrinology consultation. She improved transiently (ABG-PH-7.3, PO2102.3mmHg, PCO2-36.9mmHg, HCO3-18.7 mEq/L, Base Exess- -7.2,) but subsequently required high pressures (PIP$23 \mathrm{~cm} \mathrm{H}_{2} \mathrm{O}$, PEEP-6 $\mathrm{cm} \mathrm{H}_{2} \mathrm{O}$ ) and $100 \%$ Fio2 to maintain SPO2 of more than $90 \%$. She also required a NS bolus and ionotropes for hypoperfusion and hypotension. She was started on empirical antibiotics after sending blood cultures. 2D echo revealed severe pulmonary arterial hypertension and small patent ductus arteriosus with bidirectional shunt and a small mid muscular VSD with bidirectional shunt. Complete blood counts were normal. Serum sodium $129 \mathrm{mEq} / \mathrm{L}$, potassium $4.5 \mathrm{mEq} / \mathrm{L}$, Ionised calcium $0.968 \mathrm{mEq} / \mathrm{L}$ which were treated as per standard protocol. Initial septic screen was negative. Baby had repeated episodes of desaturations and increased pressure requirements on ventilator and had refractory shock. Blood gas showed worsening respiratory and metabolic acidosis (PH-7.069, $\mathrm{PCO}_{2}-51.6 \mathrm{mmHg}, \mathrm{PO}_{2}-35.9 \mathrm{mmHg}, \mathrm{HCO}_{3}^{-}$$14.7 \mathrm{mEq} / \mathrm{L}$ BE- -15.8). Despite all the efforts she passed away at 77 hours of life due to hypoxemic respiratory failure and refractory shock.

Autopsy showed a) Bilateral hypoplastic lungs with features of hyaline membrane disease b) Intact diaphragm c) Thyroid showed diffuse goiter with solid parenchyma with a few cysts present mostly in the periphery d) Thymic hypoplasia with lymphocyte depletion e) Eleven pairs of ribs f)Fifth middle phalangeal bone of both hands are hypoplastic g) Lower femoral epiphysis unossified. Genetic testing could not be done as parents denied consent.

\section{Discussion}

We have presented a 35 week female neonate with congenital hypothyroid goiter and severe hypoxemic respiratory failure postnatally. She was found to have pulmonary hypoplasia on autopsy. Pulmonary hypoplasia is classified as primary and secondary pulmonary hypoplasia. Abnormalities of the transcription factors and growth factors that regulate early lung morphogenesis cause primary pulmonary hypoplasia. Secondary pulmonary hypoplasia is compromised lung development secondary to reduction of the chest cavity by a mass, pleural effusion, external compression or oligohydramnios due to fetal renal anomalies, early rupture of membranes, or the absence of fetal breathing movements [1]. An enlarged fetal thyroid can cause tracheal and esophageal compression that can result in polyhydramnios antenatally [5] and can also cause respiratory compromise at delivery and baby may require ex utero intrauterine therapy(EXIT) to secure airway [6].

Thyroid hormone plays a crucial role in structural and functional maturation of lungs. Corticosteroids and thyroid hormones accelerate lung maturation by increasing surfactant synthesis and promoting lung fluid absorption. Thyroid transcription factor 1 (TTF-1), which is a product of NKX2-1 gene along with various transcriptional and growth factors plays a crucial role in lung development [7-10]. In the lung, NKX2-1 gene expression occurs in type II pneumocytes [8] and in the brain, NKX2-1 is specifically expressed in neurons of the hypothalamus [11, 12].Studies showed that transgenic mice null for NKX2-1exhibit complete absence of lung branching [9, 13]. Studies also reported that mutations in NKX2-1 gene causes brain-lungthyroid syndrome characterized by congenital hypothyroidism, neonatal respiratory distress syndrome and benign hereditary chorea. Normal fetal lung growth depends on the presence of fetal breathing movements and fetal breathing is a stimulus for lung growth [14, 15]. Impaired fetal breathing movements may cause lung maldevelopment resulting in lung hypoplasia.

Neonates with pulmonary hypoplasia will present with respiratory distress at birth, decreased breath sounds, normal or bell shaped chest with or without scoliosis and low volume lungs on chest $\mathrm{x}$ ray and severe hypoxemia. Most neonates will require mechanical ventilation at birth including HFOV (High frequency oscillator ventilation) and may require ECMO for severe hypoxemic respiratory failure. The mortality will be very high with pulmonary hypoplasia $[16,17]$. In a review by D.E. Odd et al, showed that with only three out of more than 28 babies survived to discharge from NICU. Most infants were died of respiratory failure [17]. In our case baby was died at 77hours of life.

The lung hypoplasia in our case could be due to both primary and secondary pulmonary hypoplasia. Genetic etiology is possible, as previous baby was also died of similar illness and dysmorphism in the present baby and history of consangunous parentage, although the genetic workup could not be done in our case and may also be secondary to large fetal goiter obstructing fetal breathing movements.

\section{Conclusion}

We report a case of congenital hypothyroid goiter along with pulmonary hypoplasia, which could be due to underlying genetic etiology as the baby also had facial dysmophysm and skeletal hypoplasia.

\section{Acknowledgement}

We sincerely thank Department of Fetal Medicine and Department of Perinatal Pathology, Mediscan systems, Chennai.

\section{References}

[1] Crowley M: Neonatal respiratory disorders. Fanaroff and Martin's Neonatal-PerinatalMedicine. Volume 2. 10th edition. Martin R, Fanaroff A and Walsh, M (ed): Philadelphia, Elsevier; 2015. 2:1113-1136.

[2] Kimura S, Hara Y, Pineau T, et al. The T/ebp null mouse: thyroid-specific enhancer-binding protein is essential for the organogenesis of the thyroid, lung, ventral forebrain, and pituitary. Genes Dev. 1996;10(1):60-69.

[3] Michel A. A. P. Willemsen, Guido J. Breedveld, Siep Wouda, European Journal of Pediatrics, 2004, Volume 164, Number 1, Page 28.Brain-Thyroid-Lung syndrome: a patient with a severe multi-system disorder due to a de novo mutation in the thyroid transcription factor 1 gene 
[4] Corbacioglu Esmer A, Gul A, Dagdeviren H, Turan Bakirci I, Sahin O. Intrauterine diagnosis and treatment of fetal goitrous hypothyroidism. J Obstet Gynaecol Res. 2013;39:720-723

[5] Mayor-Lynn KA, Rohrs HJ, Cruz AC, Silverstein JH, Richards D: Antenatal diagnosis and treatment of a dyshormonogenetic fetal goiter.J Ultrasound Med 2009;28:67-71.

[6] Sriram P, Femitha P, Nivedita Mondal, Jailani M, Ajayan P, Vishnu Bhat B. Neonatal Dyshormonogenetic Goitre- A Case Report Curr Pediatric Research 2011; 15 (1): 51-53

[7] Mendelson CR, Boggaram V. Hormonal and developmental regulation of pulmonary surfactant synthesis in fetal lung. Baillieres ClinEndocrinol Metab. 1990;4:351-378

[8] Barker PM, Strang LB \& Walters DV. The role of thyroid hormones in maturation of the adrenalinesensitive lung liquid reabsorptive mechanism in fetal sheep. Journal of Physiology. 1990 May;424:473-85.

[9] Tovar JA, Qi B, Diez-Pardo JA et al. Thyroid hormones in the pathogenesis of lung hypoplasia and immaturity induced in fetal rats by prenatal exposure to nitrofen. $\mathbf{J}$ Pediatr Surg. 1997 Sep;32(9):1295-7.

[10] Maeda Y, Davé V, Whitsett JA. Transcriptional control of lung morphogenesis. Physiol Rev. 2007 Jan;87(1):219-44.

[11]Lazzaro D, Price M, de Felice M, Di Lauro R.The transcription factor TTF-1 is expressed at the onset of thyroid and lung morphogenesis and in restricted regions of the foetal brain.Development. 1991 Dec;113(4):1093-104

[12] Kleiner-Fisman G, Calingasan NY, Putt M, Chen J, Beal MF, Lang AE. Alterations of striatal neurons in benign hereditary chorea. Mov Disord 2005 Oct;20(10):1353-7.

[13] Whitsett JA, Matsuzaki Y. Transcriptional regulation of perinatal lung maturation. Pediatr Clin North Am. 2006;53:873-887

[14] Kitterman JA. The effects of mechanical forces on fetal lung growth Clin Perinatol. 1996 Dec; 23(4):727-40.

[15] Wigglesworth JS, Desai R: Effects on lung growth of cervical cord section in the rabbit fetus. Early Hum Dev 3:51, 1979

[16] Jui-ShengHsu, Yu-Sheng Lee, Chin-Hsuan Lin et al. congenital pulmonary hypoplasia of a neonate. Journal of the Chinese Medical Association, Volume 75, Issue 2, February 2012, Pages 87-90.

[17] D.E. Odd, M.R. Battin, L. Hallam, D.B. Knight Primary pulmonary hypoplasia: a case report and review of the literature.J Paediatr Child Health, 39 (2003), pp. 467469 